\title{
Classroom-Based Physical Activity: Minimizing Disparities in School-Day Physical Activity Among Elementary School Students
}

\author{
Hannah G. Calvert, Matthew T. Mahar, Brian Flay, and Lindsey Turner
}

\begin{abstract}
Background: Evidence of the positive effects of school physical activity (PA) interventions, including classroom-based PA (CBPA), is rapidly growing. However, few studies examine how variations in scheduled PA opportunities and teacherimplemented CBPA affect students' PA outcomes. Methods: Teachers at 5 elementary schools attended training on how to implement CBPA. Data on school-day PA opportunities [physical education (PE), recess, and CBPA] were obtained via calendar and teacher-recorded CBPA logs. Daily step counts were measured via accelerometry in 1346 students across 65 classrooms in first through fifth grades. Results: PE, recess, and CBPA contributed significantly to students' daily steps. Males accrued more steps than females over the school day, during PE, and during recess. No gender disparity was seen in the amount of additional steps accrued during CBPA. Overall step counts were lower among fifth-grade students versus first-grade students, but CBPA attenuated this difference such that grade-level differences were not significant in fifth-grade students who received CBPA. Conclusions: Gender disparities in step totals were present on PE and recess days, but not on CBPA days. CBPA appears to provide equal PA benefits for both genders and to potentially minimize the decline in PA among older students.
\end{abstract}

Keywords: steps, physical activity breaks, movement integration, professional development

Primary prevention efforts for obesity and related chronic diseases in young populations should be a central aim of school health practices. ${ }^{1}$ Schools have a unique ability not only to address energy intake and nutrition, but also to help children meet minimum standards for daily engagement in health-enhancing physical activity (PA). ${ }^{2,3}$ Research has shown that school-based PA interventions are effective for improving health outcomes and also for improving educationally relevant behavioral outcomes such as time on task ${ }^{4-6}$ and academic achievement. ${ }^{7,8}$ To experience optimal health benefits, it is recommended that children aged 617 years accrue at least 60 minutes of moderate to vigorous PA (MVPA) per day. ${ }^{9}$ Several studies have provided evidence that elementary-school-aged children need at least 12,000 steps daily to reach this target. ${ }^{10-12}$ As a large portion of children's days are spent at school, the Institute of Medicine ${ }^{3}$ has recommended that children achieve at least half of their PA quota during school, which equates to 30 minutes of MVPA, or taking approximately 6000 steps, during regular school hours. ${ }^{13}$

Multiple opportunities for engaging in structured and unstructured PA can occur throughout the school day. Physical education (PE) is structured, utilizing purposeful learning objectives and curricular standards to educate students about movement, fitness, and health. ${ }^{14}$ Recess, which is often unstructured, allocates time for free play and social growth, ${ }^{15}$ and children can accrue substantial amounts of PA during this time. ${ }^{16-18}$ In addition, schools seeking to create optimal environments for the health and learning of their students are encouraged to provide as many opportunities for PA as possible, including in the classroom. ${ }^{3,19}$ Common examples of

Calvert, Flay, and Turner are with the College of Education, Boise State University, Boise, ID. Mahar is with the School of Exercise and Nutritional Sciences, San Diego State University, San Diego, CA. Calvert (hannahcalvert898@boisestate.edu) is corresponding author. classroom-based PA (CBPA) include infusing PA into otherwise sedentary lessons (eg, students jumping while practicing multiplication) or using PA during a break between blocks of seated instruction. ${ }^{19}$

Integration of PA into aspects of the school day other than $\mathrm{PE}$ and recess is a key part of comprehensive school PA programs. ${ }^{20,21}$ Several national organizations support this concept, and many state-based initiatives and online resources exist to support teachers. Data from a nationally representative sample of 640 US public elementary schools in 2013-2014 indicated that although over $70 \%$ of school administrators reported some use of CBPA at their school, the number of teachers engaged in the practice was often less than 50\%. ${ }^{22}$ However, given the growing evidence base showing that CBPA can improve student on-task behavior, ${ }^{5,23,24}$ the integration of PA into lessons should be viewed as an effective classroom management strategy.

Despite the expanding evidence on the benefits of CBPA implementation for school-day PA levels in children,, $25-30$ there remains a need to examine these PA outcomes when CBPA opportunities are quantified. Further, it is important to consider the variations in duration and frequency of CBPA that are inherent when delivered by teachers, and how the changes in daily "dose" of CBPA may relate to student PA levels. ${ }^{31}$ The current study examined how CBPA contributes to school-day PA in the form of total school-day step counts, when elementary school teachers implement CBPA as they choose. Specifically, we investigated the contributions of regularly scheduled PA opportunities (PE and recess), plus CBPA, toward the step counts accrued by students (across grade level and gender) during regular school hours. We hypothesized that PE and recess would facilitate the most steps, and CBPA would facilitate fewer steps, while still positively contributing to school-day PA. 


\section{Methods}

The institutional review board at Boise State University approved this study. School administrators and teachers provided written consent for study participation. Prior to the collection of student data, parents were notified of the study and provided the opportunity to decline for their child to participate (none did so). Children were also given the opportunity to decline to wear accelerometers (none did so). All data collection was anonymous at the student level, with the only 2 student characteristics known to the researchers being classroom (ie, grade) and gender.

\section{Participants}

These data were gathered as a part of a study that examined the implementation of CBPA and impacts on student outcomes at 5 public elementary schools during the 2015-2016 and 2016-2017 school years. For this study, classrooms in each school contributed 1 week of data during their semester of CBPA implementation. The demographic characteristics of schools are presented in Table 1. To preserve privacy, school characteristics are reported in ranges. Among the 5 schools, 3 were rural and 2 were suburban, with student enrollment ranging from $\sim 350$ to more than 550 students. All schools served students in kindergarten through fifth grade, and all schools served high-need communities, as indicated by high rates of student eligibility for free/reduced-priced meals (a proxy for socioeconomic disadvantage). Teachers varied in their number of years of experience, and 2 schools had a majority of early career teachers, within the first 5 years of practice.

Within the 5 schools, data were obtained from 67 classrooms. In each classroom, students wore the accelerometers for a full week; the total number of days the device was worn by each student ranged from 1 to 5 , with a mean of 4.16 observations (days) per student. A total of 5794 student-day observations were collected from 1394 students (52\% male). After 184 observations were removed from analysis due to questions of fidelity to the data collection protocol (see "Data Analysis" section), the final dataset included 5610 observations from 1346 students in 65 classrooms.

\section{PA Tracking}

Low-price commercially available accelerometers have been shown to provide accurate data regarding step counts in adults. ${ }^{32}$ Other work has shown steps to correlate with MVPA, providing a credible representation of PA in children. ${ }^{33}$ The present study used the Jawbone UP Move ${ }^{\mathrm{TM}}$ (San Francisco, CA) triaxial accelerometer to measure step counts. A subsample of participants also wore ActiGraph GT3X (Pensacola, FL) accelerometers at the same location on their right hip, allowing for the examination of the validity of the Jawbone's measurement of steps. Full details of the validity evidence are provided elsewhere. ${ }^{34}$ The Jawbone's measurement of step counts had acceptable accuracy (intraclass correlation coefficient $=.93$ ), with a slight bias for undercounting steps compared with ActiGraphs (mean difference $=-568$ steps). The Jawbone device had a rubber case with a clip and could be worn attached to clothing anywhere on the body per manufacturer specifications. All participants in this study were instructed to attach the device to their waistband at their right hip. The Jawbone was selected due to its low price, its capability to store multiple days of step data, and the lack of an overt numerical display that may provoke wearer reactivity.

\section{Protocol}

All teachers participated in a 2-part professional development session for integrating PA into classroom teaching. Teachers were asked to provide their classes with as many CBPA opportunities as they felt comfortable with and to try to facilitate at least 1 CBPA bout per day. Teachers were given a booklet of energizers, ${ }^{35,36}$ all had access to GoNoodle ${ }^{\circledR}$ (a web-based tool with activity videos), and all were encouraged to also make their own CBPA activities. Printed CBPA tracking logs were given to teachers to track the number, type, and duration of the physical activities their classes engaged in each day. Classroom scheduling information was obtained from the school's master calendar (ie, regarding the day and duration of any scheduled PE time, and expected timing of recess). Based on the master schedule, an anticipated schedule was provided to all teachers, which they were asked to confirm or correct, and to make notes about any schedule changes (eg, recess or PE cancellations, substitute teachers).

Accelerometers were delivered to each participating classroom within a given school on Friday afternoon or just before the start of class on Monday morning, and each classroom teacher was given verbal and written instructions for the measurement week. Teachers were provided a script for describing the project to the students, which included the elements of assent and providing the opportunity for students to decline to participate. Students were asked to clip the device to their right hip by attaching it to their waistband. Each student was assigned an accelerometer with a unique numeric code to wear for the whole week. Students wore the

Table 1 Characteristics of Participating Elementary Schools

\begin{tabular}{|c|c|c|c|c|c|}
\hline & School A & School B & School C & School D & School E \\
\hline \multicolumn{6}{|l|}{ Student characteristics } \\
\hline White non-Hispanic/Latino students, $\%$ & $80-90$ & $70-80$ & $40-50$ & $50-60$ & $40-50$ \\
\hline Hispanic/Latino students, $\%$ & $10-20$ & $20-30$ & $50-60$ & $30-40$ & $50-60$ \\
\hline Students eligible for free/reduced-priced meals, $\%$ & $50-60$ & $40-50$ & $80-90$ & $60-70$ & $80-90$ \\
\hline Title 1 status & Yes & Yes & Yes & Yes & Yes \\
\hline \multicolumn{6}{|l|}{ Teacher characteristics } \\
\hline Number of self-contained classroom teachers & 21 & 18 & 22 & 16 & 20 \\
\hline Median number of years teaching, $y$ & 7 & 6 & 5 & 15 & 5.5 \\
\hline Range of years teaching, $y$ & $<1-34$ & $<1-39$ & $<1-16$ & $1-32$ & $1-20$ \\
\hline Number of early career teachers $(\leq 5 \mathrm{y})$ & 9 & 9 & 12 & 4 & 10 \\
\hline
\end{tabular}

Note. To preserve school privacy, demographic characteristics are shown in decile ranges. 
accelerometer from the beginning of instruction in the morning until the end of the school day, at which time it was removed and stored in the student's desk or elsewhere in the classroom. Data were collected from each student over 4 or 5 consecutive days, depending on the schedule of the school. One school operated on a 4-day (Mon-Thu) schedule, and the other 4 operated on a 5-day (Mon-Fri) schedule. The accelerometers were picked up at the end of each classroom's week of accelerometer data collection, along with each teacher's confirmed calendar information and CBPA tracking log.

\section{Data Analysis}

Classroom calendar data (minutes of daily PE and recess) and CBPA logs were entered into a database. Teachers who returned logs with days left blank were given a " 0 " for minutes of CBPA on the days when entries were not recorded. There were many variations in the types of CBPA patterns reported by teachers each day (eg, 1 bout of $10 \mathrm{~min}, 4$ bouts of $3 \mathrm{~min}$, etc). These were entered verbatim but were collapsed for analysis, coded as the total number of minutes of CBPA each day: none, 1-5 minutes, 6-10 minutes, and more than 10 minutes. During data entry, the research team made notes about the credibility of the logs: Logs were flagged for additional consideration if all were written in the same color ink (ie, all entries possibly written on one day), included inaccurate dates (ie, weekends, holidays, or other days with no school), or other questionable patterns such as potentially out of range information (eg, unusually high amounts of activity such as two 15-min bouts per day every day). Two teachers' CBPA records were excluded (thereby removing 184 student-day observations) from analysis due to the reasons listed previously.

For accelerometer initialization, a unique account was created for each device within the free Jawbone UP mobile application. Activity data were synced by logging into the device account and enabling the Bluetooth data upload. A data file containing daily activity summaries was downloaded in spreadsheet format. Data were coded for each week of wear (ie, assigned to a classroom, based on date and location of the device that week). The Jawbone devices do not provide a calculation of total minutes of wear time, but activity start and end times were available on each daily summary. Data were screened for valid days of wear by (1) manually calculating minutes of wear by taking the difference between the start and end time of wear-if the participant wore the device for $70 \%-100 \%$ of school-day minutes, it was considered a valid day of wear time - and (2) visually examining the activity graphs of all valid days within the Jawbone interface to ensure that the device was consistently worn between the start and end times.

\section{Statistical Analysis}

These data assume a nested structure, whereby multiple observations (days) were nested within students, students were nested within teachers, and teachers were nested within schools. Descriptive statistics summarize the characteristics of the sample at the student level (Table 2), and daily PA events based on teacher schedules were examined at the classroom level (Table 3). The primary analysis was a multilevel mixed-effects linear regression analysis to examine the effects of gender, grade, minutes of PE, minutes of recess, and minutes of CBPA on step count totals. Student gender, grade, minutes of PE, minutes of recess, and CBPA outcomes were entered as fixed effects in the model. A limited number of discrete responses were possible for the variables of grade $(1,2,3,4$, or 5$)$, PE minutes $(0,18,25,30,35$, or 45$)$, and recess minutes $(20,25,30,35,40,45,50$, or 60$)$. These variables were treated as ordinal (ordered categorical) variables, with the reference group being the first value in the series (eg, grade reference $=$ first grade, PE minutes reference $=0 \mathrm{~min})$. CBPA minutes were also treated as an ordinal variable $(0,1,2$, or 3$)$. Because of the interest in examining gender and grade-level differences in step counts across the different PA opportunities, several models were conducted with interaction terms to test a priori hypothesized disparities. Given literature showing that males accrue more steps than females across the school day, ${ }^{18}$ we hypothesized that males would accrue more steps than females during all PA opportunities (PE, recess, and CBPA). Similarly, given that PA levels are lower among older children, ${ }^{37}$ we hypothesized that students in upper grades would accrue fewer steps during PA opportunities than students in lower grades. Separate models, including student characteristics and classroom (scheduling) characteristics, were calculated to test gender and grade influences on step counts, varying by PE minutes, recess minutes, and CBPA minutes. All statistics were calculated using Stata/IC statistical software (version 13.1; StataCorp LP, College Station, TX).

\section{Results}

Student-level characteristics are presented in Table 2. Participant distribution was similar across genders and across all grade levels. Because schools varied substantially in the scheduling and provision of PE and recess, the school-day characteristics by classroom are presented in Table 3. All students received some PE, except for 1 classroom, for which PE class was canceled during the measurement week. Recess minutes also varied across schools, but all schools provided students with recess at lunchtime, with at least 20 minutes of recess per day for all students and often much more. A chi-square test at the classroom level examined whether CBPA was more likely to be provided by teachers on the days on which their class did not have PE class, but this was not the case $\left(\chi^{2}=\right.$ $0.745, P=.388$ ). On PE days, $73.9 \%$ of teachers provided some

\section{Table 2 Characteristics of Daily Observations $(n=5610)$ From 1346 Students}

\begin{tabular}{lcc}
\hline & $\%$ & $\mathbf{n}$ \\
\hline Grade & & \\
1 & 13.3 & 179 \\
2 & 19.5 & 262 \\
3 & 25.3 & 341 \\
4 & 21.7 & 292 \\
5 & 20.2 & 272 \\
Gender & & \\
Female & 48 & 646 \\
Male & 52 & 700 \\
Number of observations from each school & \\
School A (14 teachers) & 19.4 & 1089 \\
School B (8 teachers) & 13.7 & 770 \\
School C (16 teachers) & 27.8 & 1558 \\
School D (11 teachers) & 12.4 & 695 \\
School E (16 teachers) & 26.7 & 1498 \\
\hline
\end{tabular}


Table 3 Weekly Amounts of PE and Daily Amounts of Recess, per Classroom/Teacher, by Grade

\begin{tabular}{|c|c|c|c|c|c|}
\hline \multirow[b]{2}{*}{ Grade } & \multirow[b]{2}{*}{ Total no. of teachers } & \multicolumn{2}{|l|}{ PE minutes per week } & \multicolumn{2}{|l|}{ Daily recess minutes } \\
\hline & & Modal response (\% of teachers) & Range & Modal response (\% of teachers) & Range \\
\hline 1 & 10 & $45(70)$ & $25-90$ & $45(34)$ & $20-50$ \\
\hline 2 & 13 & $45(39)$ & $35-90$ & $45(33)$ & $20-50$ \\
\hline 3 & 16 & $45(31)$ & 0-90 & $50(32)$ & $20-60$ \\
\hline 4 & 14 & $60(29)$ & $25-90$ & $40(40)$ & $20-40$ \\
\hline 5 & 12 & $90(33)$ & $30-90$ & $35(45)$ & $20-45$ \\
\hline
\end{tabular}

Abbreviation: PE, physical education.

CBPA, while $26.1 \%$ of teachers did not; on non-PE days, $68.2 \%$ did and $31.8 \%$ did not.

\section{Main Effects}

Table 4 presents a fully adjusted model including all covariates, but not hypothesized interaction terms. As expected, there were several significant main effects. After adjusting for PE time, recess time, and other covariates in the model, females took 958 fewer steps per school day than males. Fifth-grade students accrued 855 fewer steps than first-grade students. On days on which students received PE for 25 minutes or more, students' step counts were higher than on days with no PE. The highest step count among PE categories was observed on days with 35 minutes of PE (3867 more steps than days with no PE). More minutes of recess were also associated with higher step counts. The highest step count among recess categories was observed for 45 minutes of recess (1801 more steps than days with 20 min of recess). A significant positive association was found between minutes of CBPA and total step counts, such that providing any CBPA resulted in significantly higher steps counts compared with days with 0 minute of CBPA. The highest step count for CBPA categories was observed for days with 1-5 minutes of CBPA, showing 353 more steps accrued than days with no CBPA.

\section{Gender and Grade Interaction Effects}

We tested several hypothesized interactions between gender and each of the 3 types of PA opportunities (PE, recess, and CBPA), and between grade and types of PA opportunities. Importantly, a significant interaction emerged between CBPA minutes and grade level, whereby students in fifth grade showed significantly higher steps across increasing CBPA categories compared with students in first grade. As shown in Figure 1, the step counts for first-grade students were above 5000 steps per day for all categories of CBPA, but for fifth-grade students, step counts varied significantly depending on whether their teacher used CBPA. In fifth grade, students receiving 0 minutes of CBPA had the lowest step counts, but significantly more steps were attained by students who received CBPA for 15 minutes $(b=644.5, P<.01), 6-11$ minutes $(b=545.4, P<.01)$, and $11+$ minutes $(b=731.9, P<.01)$, bringing them close to the total step counts for first-grade students. No consistent grade-level disparities for steps accrued in PE or recess were found.

We also tested gender interactions for each of the PA opportunities. The relationship between steps and CBPA minutes did not vary by gender, but significant interactions were found for PE and recess. The gender by $\mathrm{PE}$ interaction revealed that males accrued more steps than females on days that had PE class for 35 minutes $(b$ $=2224.6, P=.001)$ and 45 minutes $(b=364.4, P=.001)$, versus
Table 4 Results of Multilevel Linear Regression Model to Predict Student-Level Daily Step Count, With StudentLevel and Classroom-Level Covariates

\begin{tabular}{|c|c|c|}
\hline & Steps $^{a}$ (SE) & $b$ \\
\hline \multicolumn{3}{|c|}{ Student-level variables } \\
\hline \multicolumn{3}{|l|}{ Gender } \\
\hline Males ${ }^{\mathrm{b}}$ & $5521(47)$ & \\
\hline Females & $4563(47)$ & $-957.9 * * *$ \\
\hline \multicolumn{3}{|l|}{ Grade } \\
\hline $1^{\mathrm{b}}$ & $5212(97)$ & \\
\hline 2 & $5245(84)$ & 33.3 \\
\hline 3 & $5451(69)$ & $240.1^{*}$ \\
\hline 4 & $5023(84)$ & -188.7 \\
\hline 5 & $4357(79)$ & $-854.4 * * *$ \\
\hline \multicolumn{3}{|c|}{ Classroom-level variables } \\
\hline \multicolumn{3}{|l|}{ PE minutes } \\
\hline $0^{\mathrm{b}}$ & 4763 (36) & \\
\hline 18 & $4498(229)$ & -264.2 \\
\hline 25 & $5522(79)$ & $759.7 * * *$ \\
\hline 30 & $5423(85)$ & $660.1 * * *$ \\
\hline 35 & $8630(355)$ & $3867.7 * * *$ \\
\hline 45 & $5927(57)$ & $1282.2 * * *$ \\
\hline \multicolumn{3}{|c|}{ Recess minutes } \\
\hline $20^{\mathrm{b}}$ & $4139(74)$ & \\
\hline 25 & 4977 (186) & $838.3 * * *$ \\
\hline 30 & $5335(89)$ & $1196.0 * * *$ \\
\hline 35 & $4738(55)$ & $599.3 * * *$ \\
\hline 40 & $4730(93)$ & $591.3 * * *$ \\
\hline 45 & $5940(87)$ & $1801.2 * * *$ \\
\hline 50 & $5252(71)$ & $1113.6^{* * *}$ \\
\hline 60 & $5421(189)$ & $1282.2 * * *$ \\
\hline \multicolumn{3}{|c|}{ CBPA minutes } \\
\hline $0^{\mathrm{b}}$ & $4925(43)$ & \\
\hline $1-5$ & $5278(54)$ & $353.6 * * *$ \\
\hline $6-10$ & $5088(55)$ & $163.0 * *$ \\
\hline $11+$ & $5156(74)$ & $230.9 * *$ \\
\hline
\end{tabular}

Abbreviations: CBPA, classroom-based physical activity; PE, physical education. ${ }^{a}$ Model-adjusted margins.

${ }^{\mathrm{b}}$ Reference group.

$* P<.05 . * * P<.01 . * * * P<.001$. 


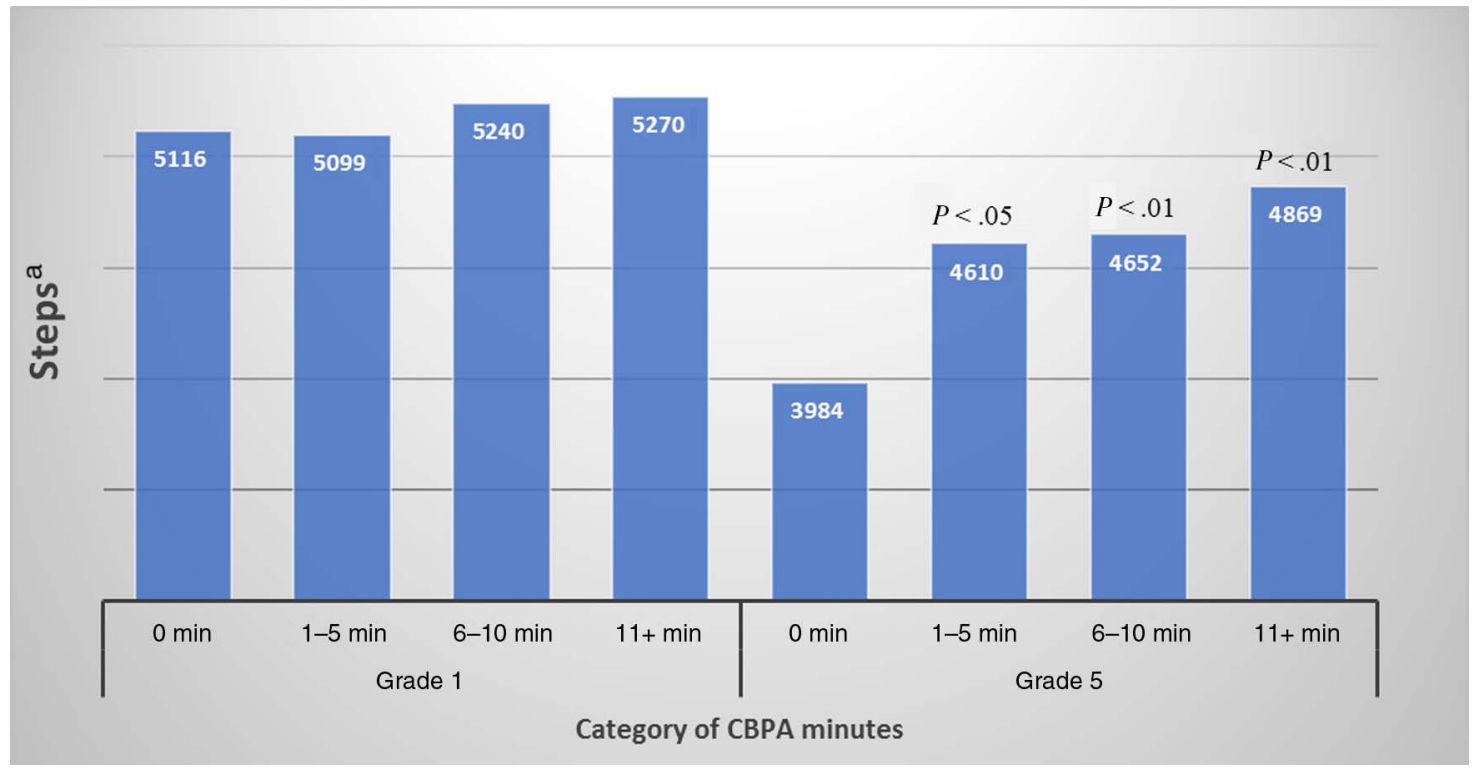

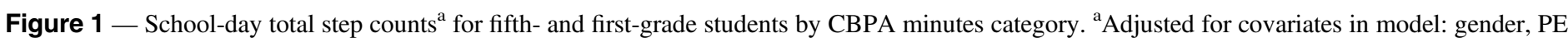
minutes, recess minutes, teacher and school effects. CBPA indicates classroom-based physical activity; PE, physical education.

no PE. Similarly, males accrued disproportionately more steps than females during recess. Step counts for males were higher on days with recess for 30 minutes $(b=568.47, P<.01)$ and 35 minutes ( $b=384.0, P<.05)$, compared with the referent category of 20 minutes.

\section{Discussion}

The results from this study indicate that PA opportunities during the school day influence step counts in young children. In addition to PE and recess, we found that minutes of teacher-reported CBPA predicted significantly higher school-day step counts. Consistent with prior studies, fifth-grade students (typically aged 10-11 y) accrued fewer steps than first-grade students (typically aged 6-7 y), and females accrued significantly fewer steps than males overall, as well as during PE and recess. Importantly, CBPA attenuated the decrease in PA among older elementary school students, and CBPA also elicited equal participation from males and females, as measured by step counts.

Previous work has shown PE to be a large contributor to steps accrued during the school day, ${ }^{18,38}$ and the current findings are consistent with that work. However, many schools-particularly those with lower student achievement on standardized tests-have cut scheduled time for PA over the last decade to prioritize academic subjects. ${ }^{3}$ Nationally representative data from 1831 elementary schools between 2009 and $2012^{39}$ showed that fewer than $20 \%$ of elementary schools provide students 150 minutes of PE time each week, which is the amount recommended by SHAPE America. ${ }^{14}$ Schools in the current study were consistent with these national trends toward providing minimal PE time in elementary schools. On the positive side, our data indicated that as few as 25 minutes of PE time in 1 session can provide a significant boost in the overall step counts of students, which is encouraging. However, this should underscore the importance of having PE daily, rather than once or twice per week.

Similar to previous work, ${ }^{17,38}$ this study also showed that more minutes of recess was associated with higher step counts. However, the gains in steps did not incrementally increase with additional recess minutes, demonstrating the variability in PA engagement among students during free play opportunities. Nationally in 2014, elementary school students received about 27 minutes of daily recess time, on average, ${ }^{40}$ which varied across schools in number of recess bouts and scheduling patterns. In the current study, students were provided with a higher average number of recess minutes daily than the national average, but PE minutes were low. With many districts facing budgetary limitations, the elimination of specialist positions, such as PE teachers, has been advocated by some sectors. ${ }^{41}$ This was not an issue in the present study, as all schools had certified specialists teaching PE. For schools facing PE cutbacks, it also may be appealing to increase recess time to compensate for lost PE minutes. However, because recess is largely unstructured and does not provide the same types of learning as PE, recess should not be viewed as an equal substitution for minutes in quality PE.

Our approach for measuring CBPA allowed us to divide daily CBPA minutes into ordered categories. Results showed that all levels of teacher-reported CBPA predicted higher daily step counts for students, compared with days when no CBPA was used. However, the highest average step total associated with CBPA in this study (353 steps) was smaller in magnitude than shown in previous CBPA intervention studies, which have reported gains of 700 or more steps. ${ }^{5,26,27}$ Unexpectedly, our data did not indicate a linear association between steps and CBPA, as the highest observed step total among CBPA categories was seen in the 1- to 5-minute group (353 more steps than no CBPA minutes), rather than the $11+$ minute group (231 more steps than no CBPA minutes). It is unclear why no dose-response relationship existed between the amount of CBPA minutes offered and step totals; however, higher levels of PE and recess minutes were not consistently associated with higher step totals either. It should be noted that step counts do not reflect the intensity of PA. Thus, students participating in short bouts of CBPA may have been doing more high-intensity movements (eg, jumping jacks or running in place) compared with during the longer CBPA bouts. Previous work has reported that teacher-delivered CBPA interventions can result in significant gains in school-day MVPA minutes. ${ }^{25,28-30}$ 
Studies of PA among elementary school-aged children often demonstrate that males accrue more PA than females, ${ }^{18,28,38,42,43}$ which this study corroborates. A gender-by-activity interaction on steps was also observed in this study, such that males accrued more steps in both PE and recess. Not all prior studies have consistently shown gender disparities in these activities. ${ }^{18,38,44}$ In the current data, there was no significant gender interaction with levels of CBPA on steps. In other words, male and female students were equally as active during CBPA. This may indicate that due to the whole-class nature or movement characteristics involved in such activities, CBPA could engage all students-both male and female - in similar amounts of PA, whereas the same is not true for PE or recess. Erwin et $\mathrm{al}^{27}$ also found males and females to respond similarly to a teacher-delivered CBPA intervention.

Much work has shown that PA patterns vary by age, often decreasing among older children. The drop in PA levels from childhood to adolescence is well documented and may begin as early as elementary school. ${ }^{43,45-47}$ The current cross-sectional data also indicate that fewer school-day steps are accrued by fifth-grade students than by first-grade students. However, we found a significant grade-level interaction with levels of CBPA on step counts. This interaction revealed that when classroom teachers utilized CBPA, it nearly eliminated the disparity in step counts between first- and fifth-grade students. In our sample, fifth-grade students whose classrooms engaged in at least 11 minutes of CBPA per day, on average, took only 401 fewer steps per school day than firstgrade students, compared with a difference of 1132 steps per school day between first- and fifth-grade students when CBPA was not offered. This has important implications for increasing PA levels among older students.

\section{Strengths and Limitations}

Strengths of this study include the examination of student PA during the school day across gender, grade, and class-specific scheduling characteristics. Teachers' CBPA implementation was assessed daily. Our study used an approach for measuring CBPA that allowed for more precise estimation of the dose of CBPA than in some other research studies that only obtain retrospective selfreports about whether any CBPA was used. The study was conducted in authentic education settings with real-world variations in scheduling and provision of PA opportunities. Teachers were encouraged to use any CBPA technique that suited them and to use even short bouts of CBPA to re-energize students, with the philosophy that "a quick PA bout is better than no PA bout." These approaches mirror how practicing teachers would most likely implement CBPA, given their time constraints and varied access to CBPA resources. This study is among the first to examine not only the differences in teachers' use of CBPA on days with varying levels of PE and recess, but also how CBPA-dependent step outcomes differ across student age and gender.

Limitations include the quantification of PA in the form of steps, which does not provide PA-intensity data such as MVPA and sedentary time and cannot entirely capture the potential healthenhancing benefits of the PA performed by teachers during this study. The tracking of CBPA was reliant on teachers' self-reportthat is, their recall and reporting of activities done each day. As with any self-report data, it is subject to reporting biases, demand characteristics, and potential inaccuracies. Although teachers were encouraged to write down their activities during or immediately after completion, this was not always realistic for the teachers; thus, some recall error in their responses is possible.

\section{Conclusions and Future Directions}

This study adds to the growing literature in support of teacherimplemented CBPA as a key element of comprehensive school PA programming. ${ }^{30}$ Results demonstrated that any amount of CBPA was associated with higher student step count totals, although we did not find a linear dose-response relationship between CBPA and steps. This is good news for those seeking to implement CBPA, as it may not take more than a few minutes of CBPA in a school day to facilitate significant gains in student PA. Future research should investigate whether short bouts of CBPA can facilitate improvements in student behavior, in line with the positive behavioral outcomes shown after longer (10-15 $\mathrm{min}$ ) moderate- to vigorousintensity classroom activities. ${ }^{24}$

We found that males and females had similar step counts when engaging in CBPA, and CBPA was an important contributor to school-day PA for older students. These findings have important implications for school policies and practices, as they reinforce the notion that CBPA should be promoted to teachers of all grades. Because PA accrual declines as children mature through elementary school, it may be particularly important for teachers in upper grades to utilize CBPA, though further work is needed to investigate whether CBPA can mitigate this decline. CBPA may also be a promising strategy to engage females in PA. Next steps for research in this area could include the use of randomized controlled trials to investigate how the implementation of CBPA in schools affects gender and grade disparities in school-day PA.

\section{Acknowledgment}

This research was supported by the Institute of Education Sciences and US Department of Education by a grant R305A150277. The opinions expressed are those of the authors and do not represent views of the institute or the US Department of Education.

\section{References}

1. Pate RR, Davis MG, Robinson TN, Stone EJ, McKenzie TL, Young JC. Promoting physical activity in children and youth: a leadership role for schools: a scientific statement from the American Heart Association Council on Nutrition, Physical Activity, and Metabolism (Physical Activity Committee) in collaboration with the Councils on Cardiovascular Disease in the Young and Cardiovascular Nursing. Circulation. 2006;114(11):1214-1224. PubMed doi:10. 1161/CIRCULATIONAHA.106.177052

2. Katzmarzyk PT, Denstel KD, Beals K, et al. Results from the United States of America's 2016 report card on physical activity for children and youth. J Phys Act Health. 2016;13(11)(suppl 2):S307-S313. PubMed doi:10.1123/jpah.2016-0321

3. Institute of Medicine. Educating the Student Body: Taking Physical Activity and Physical Education to School. Washington, DC: National Academies Press; 2013.

4. Dobbins M, Husson H, DeCorby K, LaRocca RL. School-based physical activity programs for promoting physical activity and fitness in children and adolescents aged 6 to 18. Cochrane Database Syst Rev. 2013;2(2):CD007651.

5. Mahar MT, Murphy SK, Rowe DA, Golden J, Shields AT, Raedeke TD. Effects of a classroom-based program on physical activity and on-task behavior. Med Sci Sports Exerc. 2006;38(12):2086-2094. PubMed doi:10.1249/01.mss.0000235359.16685.a3

6. Rasberry CN, Lee SM, Robin L, et al. The association between school-based physical activity, including physical education, and 
academic performance: a systematic review of the literature. Prev Med. 2011;52(suppl 1):S10-S20. doi:10.1016/j.ypmed.2011.01.027

7. Castelli DM, Centeio EE, Hwang J, et al. VII. The history of physical activity and academic performance research: informing the future. Monogr Soc Res Child Dev. 2014;79(4):119-148. PubMed doi:10. 1111/mono. 12133

8. Donnelly JE, Lambourne K. Classroom-based physical activity, cognition, and academic achievement. Prev Med. 2011;52(suppl 1): S36-S42. doi:10.1016/j.ypmed.2011.01.021

9. United States Department of Health and Human Services. 2008 Physical Activity Guidelines for Americans. Washington, DC: United States Department of Health and Human Services; 2008.

10. Adams MA, Johnson WD, Tudor-Locke C. Steps/day translation of the moderate-to-vigorous physical activity guideline for children and adolescents. Int J Behav Nutr Phys Act. 2013;10(1):49. doi:10.1186/ 1479-5868-10-49

11. Colley RC, Janssen I, Tremblay MS. Daily step target to measure adherence to physical activity guidelines in children. Med Sci Sports Exerc. 2012;44(5):977-982. PubMed doi:10.1249/MSS. 0b013e31823f23b1

12. Rowlands AV, Eston RG. Comparison of accelerometer and pedometer measures of physical activity in boys and girls, ages 8-10 years. Res Q Exerc Sport. 2005;76(3):251-257. PubMed doi:10.1080/ 02701367.2005.10599296

13. Burns RD, Brusseau TA, Fu Y, Hannon JC. Establishing school day pedometer step count cut-points using ROC curves in low-income children. Prev Med. 2016;86:117-122. PubMed doi:10.1016/j. ypmed.2016.02.018

14. Society of Health and Physical Educators (SHAPE) America. The Essential Components of Physical Education. Reston, VA: SHAPE America; 2015.

15. American Alliance for Health, Physical Education. Recess for Elementary School Students: A Position Paper From the National Association for Sport and Physical Education. Reston, VA: American Alliance for Health, Physical Education, Recreation and Dance; 2006.

16. Beighle A, Morgan CF, Le Masurier G, Pangrazi RP. Children's physical activity during recess and outside of school. $J$ Sch Health. 2006;76(10):516-520. PubMed doi:10.1111/j.1746-1561. 2006.00151.x

17. Erwin H, Abel M, Beighle A, Noland MP, Worley B, Riggs R. The contribution of recess to children's school-day physical activity. J Phys Act Health. 2012;9(3):442-448. PubMed doi:10.1123/jpah.9.3.442

18. Tudor-Locke C, Lee SM, Morgan CF, Beighle A, Pangrazi RP. Children's pedometer-determined physical activity during the segmented school day. Med Sci Sports Exerc. 2006;38(10):1732-1738. PubMed doi:10.1249/01.mss.0000230212.55119.98

19. Centers for Disease Control and Prevention. The Association Between School-Based Physical Activity, Including Physical Education, and Academic Performance. Atlanta, GA: United States Department of Health and Human Services; 2010.

20. Centers for Disease Control and Prevention. School health guidelines to promote healthy eating and physical activity. Morb Mortal Wkly Rep Recomm Rep. 2011;60(RR-5):1-76.

21. Society of Health and Physical Educators. Comprehensive School Physical Activity Programs: Helping All Students Log 60 Minutes of Physical Activity Each Day [Position Statement]. Reston, VA: Society of Health and Physical Educators; 2013.

22. Turner L, Chaloupka FJ. Reach and implementation of physical activity breaks and active lessons in elementary school classrooms. Health Educ Behav. 2017;44(3):370-375. PubMed doi:10.1177/ 1090198116667714
23. Grieco LA, Jowers EM, Bartholomew JB. Physically active academic lessons and time on task: the moderating effect of body mass index. Med Sci Sports Exerc. 2009;41(10):1921-1926. PubMed doi:10. 1249/MSS.0b013e3181a61495

24. Grieco LA, Jowers EM, Errisuriz VL, Bartholomew JB. Physically active vs. sedentary academic lessons: a dose response study for elementary student time on task. Prev Med. 2016;89:98-103. PubMed doi:10.1016/j.ypmed.2016.05.021

25. Wilson AN, Olds T, Lushington K, Parvazian S, Dollman J. Active school lesson breaks increase daily vigorous physical activity, but not daily moderate to vigorous physical activity in elementary school boys. Pediatr Exerc Sci. 2016;29(1):145-158.

26. Bartholomew JB, Jowers EM. Physically active academic lessons in elementary children. Prev Med. 2011;52(suppl 1):S51-S54. doi:10. 1016/j.ypmed.2011.01.017

27. Erwin HE, Beighle A, Morgan CF, Noland M. Effect of a low-cost, teacher-directed classroom intervention on elementary students' physical activity. J Sch Health. 2011;81(8):455-461. PubMed doi:10.1111/j.1746-1561.2011.00614.x

28. Goh TL, Hannon J, Webster CA, Podlog LW, Brusseau T, Newton M. Effects of a classroom-based physical activity program on children's physical activity levels. J Teach Phys Educ. 2014;33(4):558572. doi:10.1123/jtpe.2014-0068

29. Holt E, Bartee T, Heelan K. Evaluation of a policy to integrate physical activity into the school day. $J$ Phys Act Health. 2013;10(4):480-487. PubMed doi:10.1123/jpah.10.4.480

30. Carlson JA, Engelberg JK, Cain KL, et al. Implementing classroom physical activity breaks: associations with student physical activity and classroom behavior. Prev Med. 2015;81:67-72. PubMed doi:10. 1016/j.ypmed.2015.08.006

31. Webster CA, Russ L, Vazou S, Goh TL, Erwin H. Integrating movement in academic classrooms: understanding, applying and advancing the knowledge base. Obes Rev. 2015;16(8):691-701. PubMed doi:10.1111/obr.12285

32. Evenson KR, Goto MM, Furberg RD. Systematic review of the validity and reliability of consumer-wearable activity trackers. Int $J$ Behav Nutr Phys Act. 2015;12(1):159. doi:10.1186/s12966-014-0159-z

33. Tudor-Locke C, Craig CL, Beets MW, et al. How many steps/day are enough? For children and adolescents. Int J Behav Nutr Phys Act. 2011;8:78. PubMed doi:10.1186/1479-5868-8-78

34. Calvert HG, Turner LT, Mahar M, Carney M. Estimating Children's Physical Activity and Sedentary Behavior During the School Day: A Comparison of the Jawbone UP Move and ActiGraph Accelerometry. Boise, ID: Initiative for Healthy Schools, Boise State University; 2017. https://education.boisestate.edu/healthyschools/files/2017/10/ TR1.pdf.

35. Mahar MT, Kenny RK, Shields AT, Scales DP, Collins G. Energizers: Classroom-based Physical Activities K-2. 2006. http:// thescholarship.ecu.edu/handle/10342/5943. Accessed March 23, 2017.

36. Mahar MT, Kenny RK, Shields AT, Scales DP, Collins G. Energizers Classroom-based Physical Activities 3-5: The Way Teachers Integrate Physical Activity With Academic Concepts. 2006. http://thescholarship .ecu.edu/handle/10342/5945. Accessed March 23, 2017.

37. Fakhouri THI, Hughes JP, Brody DJ, Kit BK, Ogden CL. Physical activity and screen-time viewing among elementary school-aged children in the United States from 2009 to 2010. JAMA Pediatr. 2013;167(3):223-229. PubMed doi:10.1001/2013.jamapediatrics. 122

38. Brusseau TA, Kulinna PH, Tudor-Locke C, Ferry M, van der Mars H, Darst PW. Pedometer-determined segmented physical activity patterns of fourth- and fifth-grade children. J Phys Act Health. 2011;8(2):279-286. PubMed doi:10.1123/jpah.8.2.279 
39. Turner L, Johnson TG, Slater SJ, Chaloupka FJ. Physical activity practices in elementary schools and associations with physical education staffing and training. Res Q Exerc Sport. 2014;85(4):488-501. PubMed doi:10.1080/02701367.2014.961053

40. Centers for Disease Control and Prevention. Results From the School Health Policies and Practices Study 2014. Atlanta, GA: Centers for Disease Control and Prevention; 2015.

41. Picus LO, Odden AR. Reinventing school finance: falling forward. Peabody J Educ. 2012;86:291-303. doi:10.1080/0161956X.2011. 578986

42. Weaver RG, Crimarco A, Brusseau TA, Webster CA, Burns RD, Hannon JC. Accelerometry-derived physical activity of first through third grade children during the segmented school day. J Sch Health. 2016;86(10):726-733. PubMed doi:10.1111/josh.12426

43. Troiano RP, Berrigan D, Dodd KW, Mâsse LC, Tilert T, McDowell M. Physical activity in the United States measured by accelerometer. Med Sci Sports Exerc. 2008;40(1):181-188. PubMed doi:10.1249/ mss.0b013e31815a51b3
44. Sarkin JA, McKenzie TL, Sallis JF. Gender differences in physical activity during fifth-grade physical education and recess periods. J Teach Phys Educ. 1997;17(1):99-106. doi:10.1123/jtpe.17. 1.99

45. Chung AE, Skinner AC, Steiner MJ, Perrin EM. Physical activity and BMI in a nationally representative sample of children and adolescents. Clin Pediatr. 2012;51(2):122-129. doi:10.1177/ 0009922811417291

46. Ishii K, Shibata A, Adachi M, Nonoue K, Oka K. Gender and grade differences in objectively measured physical activity and sedentary behavior patterns among Japanese children and adolescents: a crosssectional study. BMC Public Health. 2015;15:1254. PubMed doi:10. 1186/s12889-015-2607-3

47. Trost SG, Pate RR, Sallis JF, et al. Age and gender differences in objectively measured physical activity in youth. Med Sci Sports Exerc. 2002;34(2):350-355. PubMed doi:10.1097/00005768200202000-00025 